\title{
Tezuka Osamu: el pionero en la sexualización de niñas y adolescentes representadas en el manga japonés
}

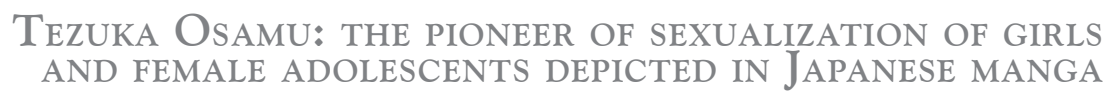

Christian Emmanuel Hernández-Esquivel*
* Universidad Autónoma del Estado de México, México Correo-e: torukajin@hotmail.com Recibido: 8 de agosto de 2020 Aprobado: 21 de enero de 2021
Resumen: Se revisan los elementos gráficos que Tezuka Osamu (1928-1989), uno de los dibujantes de historietas japonesas más famosos de todos los tiempos, utilizó para representar de manera sexual a los personajes femeninos que aparecen en sus obras, sobre todo aquellas publicadas en la década de 1960. Se retoman algunos estudios que lectores de Japón y del extranjero han hecho sobre el trabajo del artista desde la publicación de Shin Takarajima (La nueva isla del tesoro) en 1947. Se hace énfasis en los libros del crítico estadounidense Frederik L. Schodt, quien ha publicitado y popularizado en el mundo angloparlante la obra del llamado Dios del Manga. Finalmente, se describe cómo Tezuka se convirtió en el pionero en la sexualización de niñas y adolescentes representadas en el manga japonés.

Palabras clave: análisis literario; literatura asiática; literatura contemporánea; literatura popular; cultura de masas; comportamiento sexual; infancia; Japón

Abstract: The graphic elements that Tezuka Osamu (1928-1989), one of the most famous Japanese manga artists of all time, resorted to sexually depicting female characters that appear in their works, mainly those published over the 1960's decade, are analyzed. Some studies carried out in Japan and abroad have on the artist's work after the publication of Shin Takarajima (roughly, The new Treasure Island) in 1947 are retaken. Emphasis is made on the books by American critic Frederik L. Schodt, who has publicized and popularized the work of the so-called Manga god in the Englishspeaking world. Finally, the way Tezuka became the pioneer of sexualization of girls and female adolescents depicted in Japanese manga is described.

Keywords: literary analysis; Asian literature; contemporary literature; popular literature; mass culture; sexual behaviour; childhood; Japan 
INTRODUCCIÓN

El término 'sexualización' se usa en las ciencias sociales para indicar la manera en la que el sexo (y la actividad sexual) se ha vuelto cada vez más visible en los medios. Esto incluye la promoción de valores, prácticas e identidades (sexuales), en específico entre grupos poblacionales que, tradicionalmente, no han estado relacionados con estos comportamientos, por ejemplo, los niños (Attwood, 2006; 2009; Hawkes y Egan, 2008; Egan y Hawkes, 2009). La sexualización (y sus procesos mediáticos) ha sido estudiada por diversos académicos, quienes se centran en las afectaciones que tiene en el desarrollo de los infantes (APA, 2007). Otros investigadores han advertido, sin embargo, la existencia de un 'pánico moral' (fruto de una 'histeria moral'), producido por la sexualización de los niños en los medios de comunicación y el reconocimiento público de la existencia de la pedofilia (Kincaid, 1998; Sonenschein, 1998a; 1998b). Desde esta perspectiva, las representaciones sexuales de menores son condenadas por la opinión pública, lo cual evidencia cierta idealización de los infantes. Pero se olvida que los pequeños no son asexuales, sino que tienen una naturaleza sexual inherente (Egan y Hawkes, 2009).

En distintos artículos académicos, investigadores no japoneses han abordado la sexualización de la mujer y la niña representadas en los medios de este país, especialmente en el manga, pero han evitado discutir las características estilísticas y semiológicas de la tradición visual nipona desde una perspectiva histórica (Allison, 1993; 1996; Kinsella, 1995; 1998; 2000; 2002; Cooper-Chen, 2001; McLelland, 2006). Esto es muy importante porque, tal como Schodt (1983) y Downs (1990) han señalado, existen diversas diferencias legales y culturales entre la representación sexual que se hace en Japón y la que se realiza en los demás países del mundo.

En primer lugar, es necesario entender que, antes de la aprobación por la Dieta japonesa de la Act on Punishment of Activities Relating to Child Prostitution and Child Pornography, and the Protection of Children (1999), la representación sexual de niños y adolescentes no estaba prohibida por la legislación. Esto implicaba que cualquier persona podía producir imágenes sexualizadas de infantes para uso privado o comercial, explícitas o no, sin la sanción de las autoridades. Aunque el Código Penal japonés prohíbe, en su artículo 175, la exposición y distribución pública de "material obsceno", históricamente, la aplicación de esta normativa ha quedado reducida a la proscripción de mostrar vello púbico y genitales adultos. ${ }^{1}$ Así, los órganos sexuales de menores podían reproducirse, haciendo que, antes de 1999, la pornografía infantil fuera 'legal' en Japón (Bornoff, 1991; Allison, 1996; Schodt, 1996).

En segundo lugar, es preciso mencionar que la mayor parte de las niñas y adolescentes representadas en los medios visuales japoneses se asocia a la figura de la shōjo, la cual apareció a finales del siglo XIX. La palabra 'shōjo' significa, literalmente, 'niña', pero es un término que se ocupa también para designar a mujeres solteras jóvenes. Esto implica que las 'niñas' representadas sexualmente en los medios visuales nipones pueden ser menores de edad o no (Whittier

1 "Japanese obscenity laws dictate that bodies, in order to be publicly displayed, must be arranged or altered in such way that the pubis and genitalia are hidden. [...] Until 1991, the [Japanese] authorities monitoring obscenity had been rigid about certain conventions defining it. There were basically the realistic depiction of pubic hair and genitalia. The law itself is far vaguer on its definition of obscenity: that which produces a sense of shame in a 'normal' Japanese person who encounters, in public, an image or text whose primary intention or effect is to stimulate sexual desire. Legislators had adopted for years the public representation of pubic hair and genitalia as its standard for interpreting the law's notion of the obscene. On what basis this selection was made, however, and whether it was targeted at the pubis itself as the most real part of the sexual body or at a particular realistic representation of it was never clearly explicated... Although the law permits scenes of child sex in mass media, it has forbidden the explicit representation of genitalia. What results is sex acts involving undeveloped - both literally (by making the characters prepubescent) and figuratively (by keeping the image graphically simple) - genitalia" (Allison, 2000: 147-151). 
Treat, 1993; Kinsella, 1995; Ogi, 2001). Aunque la palabra shōjo se popularizó en el periodo Meiji (c. 1900), fue hasta la década de 1920, gracias al movimiento shōjo bunka, que una gran cantidad de representaciones visuales de niñas y adolescentes comenzó a aparecer tanto en revistas como en diversas publicaciones de distribución masiva. Estas funcionaban como "instrumentos especializados que dirigían la vida de las niñas" a nivel socio-cultural y educativo, y tenían como objetivo principal difundir los valores considerados "primordiales" para las mujeres, según las autoridades políticas y educativas de mediados y finales del periodo Meiji (1880-1910). Dichas expectativas eran sintetizadas en una frase: la pequeña debería convertirse en "buena esposa y madre inteligente" (ryōsai kenbo) (Rojas Martínez, 2001).

Finalmente, es importante comprender que, en la tradición visual japonesa, no todas las representaciones del cuerpo desnudo tienen como fin transmitir significados sexuales o eróticos. Tal como Downs (1990) señala, existen varios contextos en los que la desnudez se muestra abiertamente en los medios nipones: desde evocar un ambiente familiar (por ejemplo, con el uso compartido de la tina de baño) hasta situaciones cómicas relacionadas con el hecho de perder la ropa en lugares públicos. Sin embargo, eso no significa que tales imágenes carezcan de la jerarquía establecida por el patriarcado. Tal como Allison (1993) ha documentado, la mirada masculina está presente aun en las historietas dirigidas a los niños. Y, en el caso de la obra de Tezuka osamu, aunque existen varias descripciones gráficas parciales del cuerpo desnudo femenino, estas no tienen, en el contexto en que se presentan, una intención sexual per $s e^{2}$

2 En Hi no tori: reimei-hen 『火の鳥』黎明編 (Pájaro de fuego: capítulo del amanecer, 1967), vemos cómo Gusuri グスリ, doctor extranjero, ausculta a Hinaku ヒナク, una joven que yace enferma en cama, mientras los médicos de la tribu miran molestos. En otra viñeta, Hinaku, convertida en mamá y atrapada con sus hijos en una cueva, mira las estrellas del cielo por un agujero que existe en el techo. La mujer lleva

\section{El legado de Tezuka Osamu}

De acuerdo con Frederik L. Schodt (1983), Tezuka Osamu fue el verdadero creador del género shōjo manga porque sus innovaciones gráficas y narrativas influenciaron las obras de otros artistas. Al ser el primer dibujante de historietas japonesas noveladas para niñas, Tezuka popularizó una serie de elementos estilísticos que persisten en los shōjo manga hasta nuestros días: una trama romántica, locaciones en el extranjero, heroínas con ojos grandes y cierta ambigüedad sexual. Pero la conformación iconográfica de la shōjo tuvo que ver más con la popularización e imitación del trabajo de las dibujantes mujeres agrupadas en el 24-nen gumi que con la obra de Tezuka (Rojas Martínez, 2001; Gravett, 2004). El mangaka logró una renovación del concepto de la shōjo mediante sus personajes femeninos: desde Mitchi, la niña-robot que aparece en Metoroporisu (Metrópolis, 1949), hasta la princesa Zafiro, la protagonista andrógina de Ribon no kishi ( $\mathrm{La}$ princesa caballero, 1953), pasando por la niñainsecto de Konchū shōjo no hōrōki (Andanzas de la niña insecto, 1955), su representación de la figura infantil femenina distaba mucho del estereotipo de la 'buena esposa y madre inteligente'.

En opinión de los críticos japoneses, en las obras de Tezuka Osamu se encuentran numerosas referencias que, pese a no ser gráficas o explícitas, causaron reacciones adversas en los lectores de la posguerra. Según el antropólogo social Ōtsuka Eiji (2004), estos dibujos muestran un "erotismo que carece de carne" (niku wo kaita erotishizumu). Para el crítico de manga Yonezawa Yoshihiro (2010), contienen representaciones visuales que introdujeron a los niños al mundo del erotismo. El psiquiatra Tamaki Saitō

\footnotetext{
el pecho descubierto porque, en la historia, ella y sus hijos viven como en la época de las cavernas. En una escena más, la reina Himiko 女王ヒミコ deja expuesto su seno enfermo al tratar de levantarse del lecho. Estas imágenes, al no ser explícitas, no tienen intencionalidad sexual y solo sirven como referencias visuales para la trama. Las tres fueron publicadas, por primera vez, en la revista de historietas COM.
} 
(2004) afirma que los personajes femeninos creados por Tezuka tienen cierto "encanto sexual", además de que sus historias abordan temas que no son adecuados para los menores: pedofilia, homosexualidad, travestismo y fetichismo. Finalmente, el autor Nagayama Kaoru (2006) ha propuesto que estas obras son un punto nodular en la aparición de las historietas japonesas sexuales contemporáneas.

Con todo esto, Tezuka es identificado como el pionero en la sexualización de historietas japonesas para niños. Pero, tal como se ha indicado arriba, la mayor parte de las representaciones del cuerpo desnudo femenino en su trabajo no son sexualmente explícitas, como las que se encuentran en los ero-manga modernos. Además, no fueron publicadas en revistas dirigidas a menores (su obra apareció, por ejemplo, en COM [1967-1973], cuyo público estaba conformado por jóvenes y adultos). Finalmente, con la excepción de Uran, de Tetsuwan Atomu (Astro Boy, 1951); y Merumo, de Fushigina Merumo (La maravillosa Melmo, 1970), la mayor parte de las 'niñas' representadas por Tezuka no eran precisamente menores de edad, sino personajes femeninos que tenían las características estilísticas de la figura de la shōjo.

Para Ōtsuka Eiji (2004), Tezuka Osamu estableció un estilo en el cual la corporeidad y la carnalidad no aparecían de manera gráfica. Esto implicaba, en el caso del desnudo femenino, una intención no erótica que evitaba mostrar de manera explícita las características fisonómicas del cuerpo humano. Así, en la historieta $H i$ no tori: mirai-hen (1967), publicada en la revista COM, apareció por primera vez el cuerpo desnudo de una mujer con las características visuales de la shōjo: ojos grandes, pestañas nutridas, cejas desvanecidas, boca y labios diminutos, nariz afilada, cabeza redonda, hombros estrechos, torso ceñido, pechos pequeños, cintura reducida, caderas poco prominentes, cuello, brazos, muslos y piernas delgados y alargados. ${ }^{3}$ Años después, el dibujante de historietas Azuma Hideo utilizó estos códigos para representar sexualmente la figura de la shōjo, y con ello, fundar todo un nuevo género estilístico y editorial: el rorikon manga (Hernández, 2020). En 1969, el propio Tezuka dibujó gráficamente a una protagonista desnuda con "un cuerpo de carne y hueso" (namami no shintai), con lo cual se convirtió en el pionero de la sexualización de la figura de la shōjo.

Para Ōtsuka Eiji (2004), el cambio tan drástico en estos códigos visuales se debió a la incorporación de elementos estilísticos provenientes del gekiga, ${ }^{4}$ historietas japonesas en las cuales existía una tendencia muy fuerte a imitar gráficamente las características anatómicas de las mujeres de carne y hueso. En Hi no tori: hōō-hen (Pájaro de fuego: capítulo del mítico fénix, 1969), la protagonista Buchi, una muchacha de 14 años, se desnuda frente a Akanemaru para convencerlo de tener relaciones con ella. La mujer es una shōjo consciente de lo que la desnudez de su cuerpo representa para el sexo opuesto.

3 En Hi no tori: mirai-hen 『火の鳥』未囚編 (Pájaro de fuego: capitulo del futuro, 1967), encontramos a Tamami, la mūpī, ムーピーのタマミ, una forma indeterminada de vida extraterrestre, que se transforma, asumiendo el aspecto de una humana. Un robot construido a su imagen y semejanza espera en su celda de energía a ser activado. Ninguna de las ilustraciones representa fisiológicamente el cuerpo de la mujer, pero ostentan una serie de rasgos antropomórficos propios de los cánones estilísticos de la shōjo. El uso de estos códigos en el manga puede deberse a la aparición, en 1966, de Rikachanリカちゃん, la primera muñeca tipo Barbie de origen japonés.

4 劇画 Gekiga ('dibujos dramáticos') es el término con el que se conoce, en Japón, al género de historietas aparecidas a finales de la década de 1950 que se caracterizan por tener un estilo de dibujo y una trama sumamente realistas. Estas publicaciones se diferencian del manga comercial tanto en su estilo de dibujo, que muestra los objetos de manera casi fotográfica, como en los temas que abordan en sus tramas, los cuales están dirigidos a un público más maduro, en especial, estudiantes de preparatoria, universitarios y trabajadores jóvenes (Gravett, 2004: 40). El género se popularizó a lo largo de las décadas de 1960 y 1970 gracias a la incorporación de este tipo de historias en las revistas de manga comercial dirigidas, en especial, a un público juvenil (seinen manga 青年漫画), que aparecieron a finales de los sesenta (Shimizu, 2001: 146-149). 
Si bien desde mediados de la década de los sesenta algunas dibujantes de shōjo manga colocaron a 'mujeres' en lugar de 'niñas' como protagonistas de sus tramas, ${ }^{5}$ y pese a que el tema del enamoramiento (ren'ai) comenzó a ser superado por el del deseo (yokubō), ${ }^{6}$ fue hasta mediados de la década de 1970 cuando el amor carnal se representó de manera gráfica (Yonezawa, 2007: 158-160). De esta manera, el proceso de sexualización del shōjo manga se dio en dos frentes: 1) las historietas para niñas dibujadas por mujeres, que representaban a los personajes femeninos según las particularidades de la figura de la shōjo; y 2) los mangas creados por Tezuka, donde vemos mujeres sin carnalidad de acuerdo con las características citadas. Esta situación creó un panorama muy complejo que despertó diferentes opiniones académicas. Sin embargo, el consenso es que el amor carnal que se ilustró en los shōjo manga de la década de 1960 se convirtió en el antecedente temático y estilístico de los rediisu komikku (ladies comics), que surgieron a mediados de la década de 1980. ${ }^{7}$ Además, estas representaciones gráficas que se daban en los shōjo manga publicados en la década de 1970 no eran

5 "In the 1960s, Mizuno Hideko began representing 'women', not shōjo in a traditional sense, in the world of shōjo manga. What made her characters 'women' rather than 'children' was the theme of heterosexual love" (Ōgi, 2003: 781).

6 El enamoramiento (ren'ai 恋愛) se diferencia del deseo (yokubōo o 欲望) en los personajes femeninos de shōjo manga a partir de la existencia de goce carnal (Yonezawa, 2007).

7 En Manga! Manga! The World of Japanese Comics (1983), Frederik L. Schodt explica cómo se dio la evolución del shōjo manga hacia los rediisu komikku: "Fifteen years ago kissing scenes were regarded as radical in girls' comics, but today abortion, illegitimate birth, incest, and homosexuality have all been depicted. Nudity and scenes of lovers in bed are commonplace, even in magazines where the target reader is between eleven and thirteen. [...] In 1980 and 1981 monthly comic magazines specifically targeted at adult women were finally published. In these magazines, women artists are able to experiment with more adult themes and art styles... But as of the time this book was being written, the Japanese had not yet coined a word to describe comics for adult women. They are still called 'girls' comics"' (Schodt, 1983: 101-102). Esta situación cambió a mediados de la década de 1980, cuando las casas editoriales japonesas acuñaron el término rediisu komikku (ladies comics) para designar a las historietas con temas carnales dirigidas a mujeres jóvenes (Rojas Martínez, 2001: 74-75; Gravett, 2004: 116-123; Kinsella, 1995: 37). explícitas. Y, finalmente, los y las dibujantes que representaron sexualmente la figura de la shōjo reforzaron su estereotipo visual sin introducir en él algún cambio significativo. ${ }^{8}$ Sin embargo, ninguna de las publicaciones académicas consultadas pudo clarificar cuál fue la relación entre las primeras representaciones sexuales de la shōjo dibujadas por Tezuka Osamu y la aparición de trabajos posteriores de otros autores. No existe información que muestre en qué año, revista y género aparecieron estas obras. Ese es, precisamente, el interés de esta publicación.

\section{REFERENCIAS}

Allison, Anne (1993), “A Male Gaze in Japanese Children's Cartoons, or are Naked Female Bodies Always Sexual?", en Working Papers in Asian/Pacific Studies, Durham, Duke University Press.

Allison, Anne (1996), Permitted and Prohibited Desires: Mothers, Comics, and Censorship in Japan, Boulder, Westview Press.

Allison, Anne (2000), "Pubic Veilings and Public Surveillance: Obscenity Laws and Obscene Fantasies in Japan", en Permitted and Prohibited Desires: Mothers, Comics, and Censorship in Japan, Nueva York, Routledge, pp. 147-151.

American Psychological Association (APA) (2007), Report of the APA Task Force on the Sexualization of Girls, Washington, APA.

Attwood, Feona (2006), "Sexed Up: Theorizing the Sexualization of Culture", Sexualities, vol. 9, núm. 1, pp. 77-94.

Attwood, Feona (ed.) (2009), Mainstreaming Sex: The Sexualization of Western Culture, Londres, I. B. Tauris.

Bornoff, Nicholas (1991), Pink Samurai: Love, Marriage $\mathcal{E}$ Sex in Contemporary Japan, Nueva York, Pocket Books.

8 Como afirma Schodt, "With more and more women taking over editing functions at publishers, girls' comics have truly become a medium created by women for women. Still, girls' comics do not always reflect a higher feminist consciousness" (1983: 97). Por otro lado, "Women also absorbed representations of conventional gender roles through the various media, of course, and they developed a strong sense of identity within the patriarchal framework. [...] To write for girls at their own levels, women writers adopted a strategy of selfrepresentation, at the same time they reinforced prior images of shōjo. Although they wrote about female individuals and tried to offer their various feelings of love as a common theme of women, unless they destabilized the naturalized heterosexual gender roles, they would, after all, only impose traditional restraints of feminity upon themselves. Women could enjoy such gender images only if they agreed with their supposed position as an object of male desire" (Ogi, 2001: $173,178)$ 
Cooper-Chen, Anne (2001), "The Dominant Trope': Sex, Violence, and Hierarchy in Japanese Comics for Men", en Matthew P. McAllister, Edward H Sewell e Ian Gordon (eds.), Comics \& Ideology, Nueva York, Peter Lang.

Downs, James F. (1990), "Nudity in Japanese Visual Media: a Cross-Cultural Observation", Archives of Sexual Behavior, vol. 19, núm. 6, pp. 583-594.

Egan, Danielle R. y Gail Hawkes (2009), "The problem with protection: Or, why we need to move towards recognition and the sexual agency of children", Continuum: Journal of Media Ë Cultural Studies, vol. 23, núm. 3, pp. 389-400.

Gravett, Paul (2004), Manga: Sixty Years of Japanese Comics, Londres, Laurence King Publishing.

Hawkes, Gail L. y R. Danielle Egan (2008), "Developing the sexual child", Journal of Historical Sociology, vol. 21, núm. 4, pp. 443-465.

Hernández, Christian E. (2020), "El rorikon manga y la criminalización (global) de sus productos”, Asiadémica, núm. 15, pp. 10-29.

Kincaid, James R. (1998), Erotic Innocence: The Culture of Child Molesting, Durham, Duke University Press.

Kinsella, Sharon (1995), "Cities in Japan”, en Lise Skov y Brian Moeran (eds.), Women Media and Consumption in Japan, Honolulu, University of Hawaii Press.

Kinsella, Sharon (1998), "Japanese Subculture in the 1990s: Otaku and the Amateur Manga Movement", The Journal of Japanese Studies, vol. 24, núm. 2, pp. 289-316.

Kinsella, Sharon (2000), Adult Manga: Culture and Power in Contemporary Japanese Society, Honolulu, University of Hawaii Press.

Kinsella, Sharon (2002), "What's Behind the Fetishism of Schoolgirls' Uniforms in Japan?", Fashion Theory, vol. 6, núm. 2, pp. 215-238.

McLelland, Mark (2006), "A Short History of 'Hentai”, Intersections: Gender, History and Culture in the Asian Context, núm. 12, disponible en: http://intersections.anu.edu.au/ issue $12 /$ mclelland.html

Nagayama, Kaoru (2006), Ero-manga sutadīzu: "kairaku sōchi" toshite manga nyümon, Tokio, East Press.

Ogi, Fusami (2001), "Gender Insubordination in Japanese Comics (Manga) for Girls", en Jhon A. Lent, Illustrating Asia: Comics, Humor Magazines and Picture Books, Honolulu, University of Hawaii Press.

Ogi, Fusami (2003), "Female Subjectivity and Shoujo (Girls) Manga (Japanese Comics): Shoujo in Ladies' Comics and Young Ladies' Comics", The Journal of Popular Culture, vol. 36, núm. 4, pp. 780-803.

Ōtsuka, Eiji (2004), "Kigō toshite no sei", Otaku no seishin shi: 1980 nendai ron, Tokio, Kodansha.

Rojas Martínez, Adriana (2001), El manga en Japón: la sociedad japonesa de posguerra a través del shōjo manga, [Tesis de Maestría], El Colegio de México, México.

Saitō, Tamaki (2004), "Kyōyō kara 'shinkeishō' he -Tezuka Osamu no genzaikei-”, en Kairi no poppu sukiru, Tokio, Keisō Shobō.

Shimizu, Isao (2001), "Red Comic Books: The origins of Modern Japanese Manga”, en Jhon A. Lent, Illustrating Asia: Comics, Humor Magazines and Picture Books, Honolulu, University of Hawaii Press.
Schodt, Frederick L. (1983), Manga! Manga! The World of Japanese Comics, Tokio, Kodansha International.

Schodt, Frederick L. (1996), Dreamland Japan: Writings on Modern Manga, Berkeley, Stone Bridge.

Sonenschein, David (1998a), Pedophiles on Parade, Vol. I: The Monster in the Media, San Antonio, Texas, David Sonenschein.

Sonenschein, David (1998b), Pedophiles on Parade, Vol. 2: The popular Imagery of Moral Hysteria, San Antonio, Texas, David Sonenschein.

Whittier Treat, John (1993), "Yoshimoto Banana Writes Home: Shōjo Culture and the Nostalgic Subject", The Journal of Japanese Studies, vol. 19, núm. 2, pp. 353-387.

Yonezawa, Yoshihiro (2007), Sengo shoujo manga shi, Tokio, Chikuma Shobō.

Yonezawa, Yoshihiro (2010), Sengo ero manga shi, Tokio, Seirin Kōgeisha.

Christian Emmanuel Hernández Esquivel. Licenciado en Letras Latinoamericanas y Maestro en Psicología por la Universidad Autónoma del Estado de México (UAEM), México. Egresado de la Maestría en Estudios de Asia y África, especialidad Japón, de El Colegio de México (Colmex), México. Miembro fundador de la Asociación de Japonés del Estado de México A. C. Miembro de la Red Iberoamericana de Investigadores en Anime y Manga. Profesor de asignatura de la UAEM. 